\title{
(2) OPEN ACCESS \\ Neuraxial and general anesthesia for outpatient total joint arthroplasty result in similarly low rates of major perioperative complications: a multicentered cohort study
}

\author{
Edward Yap (1) , ${ }^{1,2}$ Julia Wei, ${ }^{3}$ Christopher Webb, ${ }^{1,2}$ Kevin Ng, ${ }^{4}$ Matthias Behrends ${ }^{2}$
}

- Additional supplemental material is published online only. To view, please visit the journal online (http://dx.doi.org/ 10.1136/rapm-2021-103189).

${ }^{1}$ Department of Anesthesia, The Permanente Medical Group, South San Francisco, California, USA

${ }^{2}$ Department of Anesthesia and Perioperative Care, University of California San Francisco, San Francisco, California, USA ${ }^{3}$ Division of Research, Kaiser Permanente, Oakland, California, USA

${ }^{4}$ Department of Anesthesia, The Permanente Medical Group, Walnut Creek, California, USA

\section{Correspondence to}

Edward Yap, Department of Anesthesia, The Permanente Medical Group, South San Francisco, California, USA; Edward.N.Yap@kp.org

Presented in part at the 2021 International Anesthesia Research Society Annual Meeting; 15 May 2021; Virtual Meeting.

Received 17 September 2021 Accepted 9 December 2021

Check for updates

(C) American Society of Regional Anesthesia \& Pain Medicine 2022. Re-use permitted under CC BY-NC. No commercial re-use. Published by BMJ.

To cite: Yap E,
Wei J, Webb C, et al.
Reg Anesth Pain Med Epub
ahead of print: [please
include Day Month Year].
doi:10.1136/rapm-2021-
103189

\section{ABSTRACT}

Background Neuraxial anesthesia when compared with general anesthesia has shown to improve outcomes following lower extremity total joint arthroplasty. It is unclear whether these benefits are present in outpatient surgery given the selection of healthier patients.

Objective To compare the effects of neuraxial versus general anesthesia on outcomes following ambulatory hip and knee arthroplasty.

Methods Multicentered retrospective cohort study in ambulatory hip or knee arthroplasty patients between January 2017 and December 2019. Primary endpoint examined 30-day major postoperative complications (mortality, myocardial infarction, deep venous thromboembolism, pulmonary embolism, stroke, and acute renal failure).

Results Of 11523 eligible patients identified, 10003 received neuraxial anesthesia, while 1520 received general anesthesia. 30-day major complications did not differ between neuraxial anesthesia and general anesthesia groups ( $1.8 \%$ vs $2.3 \%$; aOR $=0.85, \mathrm{Cl}: 0.56$ to $1.27, p=0.39$ ). There was no difference in 30 -day minor complications (surgical site infection, pneumonia, urinary tract infection; $3.3 \%$ vs $4.1 \% ; \mathrm{aOR}=0.83$,

$\mathrm{Cl}: 0.62$ to $1.14, p=0.23)$. The neuraxial group demonstrated reduced pain and analgesia requirements and had less postoperative nausea and vomiting (PONV). Median recovery room length of stay was shorter by 52 min in the general anesthesia group, but these patients were more likely to fail same day discharge (33\% vs $23.4 \% ; p<0.01)$.

Conclusion Anesthesia type was not associated with an increased risk for complications. However, neuraxial anesthesia improved outcomes that predict readiness for discharge: patients had less pain, required less opioids, and had a lower incidence of PONV, thus improving the rate of same day discharge.

Trial registration number NCT04203732.

\section{INTRODUCTION}

Total joint arthroplasties are commonly performed elective orthopedic surgeries in the USA that can dramatically improve quality of life. ${ }^{1}$ Historically, a multiday hospitalization has been common after total joint arthroplasty. More recently, these surgeries are performed with a short hospital stay or even as an outpatient surgery. ${ }^{2-4}$ The drive towards this new paradigm for reduced hospital time is multifactorial. The creation of bundled payments, the removal of total hip and knee arthroplasty from the Medicare inpatient-only procedure list, and an increased demand for these surgeries have created an economic incentive for decreasing hospital length of stay after surgery. ${ }^{4}$ Advancements in surgical techniques, improvements in anesthesia care, the development of multimodal pain management pathways, and enhanced rehabilitation and home healthcare protocols have helped make this shift possible. ${ }^{256}$

Outpatient total joint arthroplasty has been shown to be safe and feasible, having similar or possibly decreased risk of complications when compared with standard hospitalized care. ${ }^{7-9}$ With the continuing increase in demand for total joint arthroplasty and the aim of healthcare systems to provide value-based patient care, the move towards outpatient arthroplasty will likely continue. The type of anesthesia can play a critical role in establishing a successful outpatient total joint arthroplasty program. Investigations on the impact of the type of anesthesia on postoperative outcomes for total joint arthroplasty and other surgery types have consistently found a reduction in postoperative morbidity, mortality, and healthcare costs when neuraxial anesthesia was used compared with general anesthesia. ${ }^{10-14}$ However, it is unclear if the benefits of neuraxial anesthesia also exist in outpatient total joint arthroplasty given the generally healthier patient population undergoing ambulatory surgery ${ }^{15-17}$ Concurrently, general anesthesia has been suggested to enhance recovery following fast-track arthroplasty. ${ }^{18} 19$ Therefore, the optimal anesthetic technique for outpatient total hip or knee arthroplasty has yet to be determined. ${ }^{20}$

The goal of this study was to compare the effects of neuraxial anesthesia versus general anesthesia on intraoperative, early postoperative, and 30-day postoperative outcomes in patients undergoing outpatient unilateral primary total hip or knee arthroplasty. We hypothesized that neuraxial anesthesia reduces the incidence of adverse postoperative outcomes when compared with general anesthesia.

\section{METHODS}

This article was prepared according to the Strengthening the Reporting of Observational Studies in Epidemiology guidelines. 


\section{Study design}

We performed a retrospective cohort study comparing patients who received neuraxial anesthesia to those who received general anesthesia for outpatient lower extremity total joint arthroplasty. Outpatient surgery was defined as planned same day discharge as surgery day. The primary endpoint of our study was a 30-day major postoperative complication. A major complication included a composite incidence of mortality, myocardial infarction, deep venous thromboembolism, pulmonary embolism, stroke, and acute renal failure. Secondary outcomes examined a 30-day minor postoperative complication, which comprised of a composite incidence of surgical site infection, pneumonia, and urinary tract infection. Other important intraoperative and postoperative outcomes included 30-day readmission rates, surgical duration, estimated surgical blood loss, red blood cell (RBC) transfusion, length of postanesthesia care unit (PACU) stay, amount of opioid administered intraoperatively and in the PACU, PACU pain scores, incidence of postoperative nausea and vomiting (PONV) in the PACU, and failure rate for same day discharge.

\section{Setting}

Kaiser Permanente Northern California is a multicentered integrated healthcare medical system consisting of 21 medical centers in Northern California that use the same electronic medical record (EMR, Epic, Verona, WI, USA). In 2017, an outpatient total joint arthroplasty pathway was established throughout Kaiser Permanente Northern California. The pathway helped streamline preoperative medical optimization, patient education, and perioperative care for patients. The pathway included guidelines for patient selection for outpatient total joint arthroplasty, which included younger, medically optimized, non-smokers, and non-anemic patients. The guidelines were used by surgeons to screen patients, and the decision to include patients for outpatient surgery was ultimately decided by the surgeon and patient. Prior to pathway implementation, there was a preference by anesthesia departments to use neuraxial anesthesia. The choice of anesthesia after implementation was determined by the anesthesiologist and was dependent on clinical factors and patient preference. All total joints were performed in a hospital setting and not at a free-standing ambulatory surgery center. Our institution utilized a standard PACU order set for patients to receive analgesic and opioid medications on an as needed basis dependent on patient pain scores.

\section{Study population}

We identified patients aged 18 and older who underwent outpatient primary unilateral total hip or knee arthroplasties at one of our 21 medical centers between January 1, 2017 and December 31, 2019. Excluded were patients undergoing emergent, unicompartmental, oncologic tumor, fracture related, revision, and bilateral total joint arthroplasties, and patients who received both general and neuraxial anesthesia. Patients who had more than one arthroplasty during the study period had only the first surgery included. Patients undergoing outpatient total joint arthroplasty were all seen in a perioperative medicine clinic prior to surgery. The clinics exist at each hospital and help medically optimized patients using standardized workflows. The workflows included addressing chronic medical conditions such as hypertension and diabetes medication management, as well as standardize cessation of antiplatelet and anticoagulant medications to allow for the choice of neuraxial anesthesia.

\section{Exposure variable}

Our exposure of interest was type of anesthesia, neuraxial or general anesthesia, obtained through intraoperative records. Combined neuraxial and general anesthesia was not typically used in our setting and not included as an exposure variable.

\section{Outcome variables}

The 30-day postoperative outcomes were obtained using International Classification of Diseases, 10th Edition (ICD-10) codes (online supplemental table 1) documented in the EMR. The outcomes were adjudicated by one of the study's authors by confirming clinical, imaging, or laboratory documentation of diagnosis by chart review. Readmission was defined as hospital admission within 30-days of surgery discharge for any reason. Surgical site infection included superficial or deep wound infection located at the surgical incision site. Myocardial infarction included both non-ST segment elevation and ST segment elevation myocardial infarction. Pneumonia, deep vein thromboembolism and pulmonary embolism, and stroke required a diagnosis made by imaging. Acute renal failure was defined by meeting at minimum stage 1 criteria in the Kidney Disease Improving Global Outcomes criteria (Creatinine 1.5-1.9 times baseline or increase $>0.3 \mathrm{mg} / \mathrm{dL}$ ).

Perioperative medications administered were collected through the Medication Administration Record. Opioids administered was reported in Morphine Milligram Equivalents (MME). Pain scores were recorded using the Numeric Rating Scale for pain (scale from 0 to 10 ) and we calculated the average pain score during PACU stay for each patient. PONV was recorded using a postanesthetic scoring system (2 representing none/minimal, 1 moderate, 0 severe; we categorized patients as either having PONV (if they ever had a score of 0 or 1 ) or no PONV (patients only ever having a of score 2)). Surgery duration was defined as the time from procedure start to procedure end. PACU length of stay was defined as the time the patient arrived in the PACU to the time the patient met discharge criteria from the PACU. Blood loss and RBC transfusion was obtained from the EMR flowsheet. Planned same day discharge was documented in the surgical booking. Failure of same day discharge was identified by a discharge day different than the surgery date in the EMR.

\section{Statistical analysis}

Categorical data were described as frequencies (percentages) while continuous data were reported as means and SD for normally distributed data and medians and quartiles $(Q)$ for nonnormally distributed data. Bivariate analysis was performed to determine associations between outcomes and anesthesia type. Comparisons of categorical variables were performed using the $\chi^{2}$ or Fisher's exact tests. Normally distributed continuous variables were compared using Student's t test, while non-normally distributed continuous variables were compared using Wilcoxon rank-sum test. Since the outcomes from the same facility are likely to be correlated, we used hierarchical multivariable regression analysis models to control for 'clustered' data. Hospital (center) was included as a random effect, not fixed effect. We fit a random intercept model using the center (hospital) as the cluster variable. All multivariable models were adjusted by age, sex, race/ethnicity, body mass index (BMI), and American Society of Anesthesiologists (ASA) classification. We performed logistic regression to examine the associations between 30-day outcomes and the anesthesia type with adjustments for patients' demographics and clinical characteristics. Variables that were deemed clinically important or with observed statistically significant 
$\mathrm{p}$-value in the bivariate analyses were included in the final multivariable regression models. The only variables that had missingness were BMI (0.009\% missing) and Last Hemoglobin Before Surgery $(10.5 \%$ missing). We imputed BMI to be the median value of 30 in the multivariable models that included BMI as a covariate. No other variables had missing data. Models were not adjusted for multiple comparisons. Because of the potential for type I error due to multiple comparisons, findings for these analyses should be interpreted as exploratory. ${ }^{21}{ }^{22}$ Multivariable analysis outcomes were reported as adjusted ORs (aOR, 95\% $\mathrm{CI}$ ). A p-value of $<0.05$ was considered significant. All data management and analysis were performed using SAS V.9.4 (SAS Institute, Cary NC).

\section{RESULTS}

\section{Patient characteristics}

We identified 14589 patients who underwent outpatient unilateral primary total hip or knee arthroplasty from the start of 2017 through the end of 2019. We excluded 2143 patients under 18, who had emergent, oncologic tumor, fracture related, revision, and bilateral total joint arthroplasties, and patients who received both general anesthesia and neuraxial. There were 923 surgeries excluded as patients who had more than one arthroplasty during the study period. Of the 11523 patients (9866 with knee arthroplasty, 1657 with hip arthroplasty) included in the study, $1520(13.2 \%)$ had general anesthesia and 10003 (86.8\%) had neuraxial anesthesia. Baseline demographic and clinical characteristics of the cohort are presented in table 1.

The average age of patients was 68 (SD 8.9) with a small difference in age between the general anesthesia group and neuraxial group $(67.3$ vs $68.2, \mathrm{p}<0.01)$. There were more women than men $(60.3 \%$ vs $39.7 \%)$, but there was no association between gender and type of anesthesia. A higher percent of patients receiving general anesthesia were Black and Hispanic compared with those receiving neuraxial anesthesia $(9.1 \%-$ $15.5 \%$ vs $5.8 \%-12.8 \%$, respectively). Similarly, a higher percent of patients receiving general anesthesia had higher BMI, ASA classification and Charlson comorbidity index (CCI) compared with neuraxial anesthesia. Patients undergoing hip arthroplasty had a higher rate of general anesthesia compared with knee arthroplasty $(17.6 \%$ vs $12.4 \%, \mathrm{p}<0.01)$.

\section{0-Day postoperative adverse outcomes}

There were no significant differences in our primary endpoint of 30 -day major postoperative complications between the neuraxial and general anesthesia groups ( $1.8 \%$ vs $2.3 \%$; $\mathrm{aOR}=0.85,95 \%$ CI: 0.56 to 1.27). No significant difference was also found in 30 -day minor complications $(3.3 \%$ vs $4.1 \%$; a OR $=0.83,95 \%$ CI: 0.62 to 1.14$)$, and 30 -day readmission rates (2.3\% vs $3 \%$; $\mathrm{aOR}=0.86,95 \% \mathrm{CI}: 0.59$ to 1.25 ) between the two groups (figure 1). Unadjusted outcomes found a significantly lower odds for 30-day postoperative myocardial infarction in the neuraxial group compared with the general anesthesia group (unadjusted $\mathrm{OR}=0.36,95 \% \mathrm{CI}: 0.17$ to $0.76, \mathrm{p}=0.01$ ); however, after multivariable hierarchical modeling, the difference was no longer significant ( $\mathrm{aOR}=0.48,95 \% \mathrm{CI}: 0.21$ to $1.09, \mathrm{p}=0.08)$. No other significant differences were found in individual 30-day postoperative complications (table 2).

\section{Secondary outcomes}

The general anesthesia group received higher median amounts of opioids intraoperatively (40 MME (Q1-Q3: 19-65) vs 0 MME (Q1-Q3: 0-22.5); $\mathrm{p}<0.01$ ), in the PACU (36 MME
Table 1 Baseline characteristics of patients who underwent outpatient total knee or hip arthroplasty by anesthesia type

\begin{tabular}{|c|c|c|c|c|}
\hline \multirow[b]{3}{*}{ Characteristic } & \multirow[b]{2}{*}{ Total } & \multicolumn{2}{|c|}{ Anesthesia type } & \multirow[b]{3}{*}{$P$ value } \\
\hline & & Neuraxial & General & \\
\hline & $n=11523$ & $n=10003$ & $n=1520$ & \\
\hline $\begin{array}{l}\text { Mean age in years } \\
\text { (SD) }\end{array}$ & $68.0(8.9)$ & $68.2(8.8)$ & $67.3(9.2)$ & $<0.01$ * \\
\hline Sex, n (\%) & & & & 0.79 \\
\hline Male & 4577 (39.7) & $3978(39.8)$ & 599 (39.4) & \\
\hline Female & $6946(60.3)$ & $6025(60.2)$ & $921(60.6)$ & \\
\hline \multicolumn{2}{|l|}{ Race/ethnicity, n (\%) } & & & $<0.01$ \\
\hline $\begin{array}{l}\text { Non-Hispanic } \\
\text { White }\end{array}$ & $7844(68.1)$ & $6830(68.3)$ & $1014(66.7)$ & \\
\hline Asian & $931(8.1)$ & $864(8.6)$ & $67(4.4)$ & \\
\hline Black & $720(6.3)$ & $581(5.8)$ & $139(9.1)$ & \\
\hline Hispanic & $1515(13.2)$ & $1280(12.8)$ & 235 (15.5) & \\
\hline Other & $513(4.5)$ & $448(4.5)$ & $65(4.3)$ & \\
\hline BMIt†, n (\%) & & & & $<0.01$ \\
\hline Normal & $1727(15.0)$ & $1549(15.5)$ & $178(11.7)$ & \\
\hline Overweight & 3967 (34.4) & 3488 (34.9) & 479 (31.5) & \\
\hline Obese & $5828(50.6)$ & $4965(49.6)$ & $863(56.8)$ & \\
\hline ASA class, n (\%) & & & & $<0.01$ \\
\hline 1 & $172(1.5)$ & $165(1.7)$ & $7(0.5)$ & \\
\hline II & $6874(59.7)$ & $6182(61.8)$ & $692(45.5)$ & \\
\hline III & 4396 (38.2) & 3608 (36.1) & 788 (51.8) & \\
\hline IV & $81(0.7)$ & $48(0.5)$ & $33(2.2)$ & \\
\hline \multicolumn{2}{|l|}{ Surgery type, n (\%) } & & & $<0.01$ \\
\hline Knee & $9866(85.6)$ & $8638(86.4)$ & $1228(80.8)$ & \\
\hline Hip & $1657(14.4)$ & $1365(13.7)$ & $292(19.2)$ & \\
\hline \multicolumn{2}{|c|}{ Comorbidity score $\ddagger, n$ (\%) } & & & 0.01 \\
\hline 0 & $4412(38.3)$ & 3865 (38.6) & $547(36.0)$ & \\
\hline $1-2$ & $4854(42.1)$ & $4223(42.2)$ & $631(41.5)$ & \\
\hline $3+$ & $2257(19.6)$ & $1915(19.1)$ & $342(22.5)$ & \\
\hline Laterality, n (\%) & & & & 0.72 \\
\hline Left & $5470(47.5)$ & $4755(47.5)$ & $715(47.0)$ & \\
\hline Right & $6053(52.5)$ & $5248(52.5)$ & $805(53.0)$ & \\
\hline $\begin{array}{l}\text { Mean hemoglobin } \\
\text { before surgery } \\
\text { within } 3 \text { months } \\
\text { of surgery date§§ } \\
\text { (SD) }\end{array}$ & $13.6(1.4)$ & $13.7(1.4)$ & $13.5(1.5)$ & $<0.01^{*}$ \\
\hline
\end{tabular}

${ }^{*} \mathrm{P}$ value calculated with Student $\mathrm{t}$-test

t0.008\% missing BMI (one patient).

¥Charlson comorbidity index used as comorbidity score.

$\S 10.5 \%$ missing last hemoglobin before surgery (1214 patients).

BMI, body mass index; ASA, American Society of Anesthesiologists.

(Q1-Q3: 15-60) vs 15 MME (Q1-Q3: 7.5-37.5); p<0.01), and had higher reported median average (2.5 (Q1-Q3: 1.8-3.2) vs $1.5(\mathrm{Q} 1-\mathrm{Q} 3: 1.1-2.3) ; \mathrm{p}<0.01)$ and median maximum pain scores (7 (Q1-Q3: 5-8) vs 5 (Q1-Q3: 2-7); p<0.01) (table 3). We found that patients in the general anesthesia group more frequently received gabapentinoids, ketamine, alpha-2 agonist, magnesium sulfate, and corticosteroids. The neuraxial anesthesia group more frequently received non-steroidal anti-inflammatory drugs, acetaminophen, and periarticular injections. There was no difference in the use of peripheral nerve blocks between the two groups (table 4).

The general anesthesia group had higher rates of PONV in the PACU compared with the neuraxial group $(4.5 \%$ vs $3 \%$; $\mathrm{p}=0.01$ ). Median estimated blood loss was higher in the general 
Adjusted Odds Ratio $(95 \% \mathrm{Cl})$

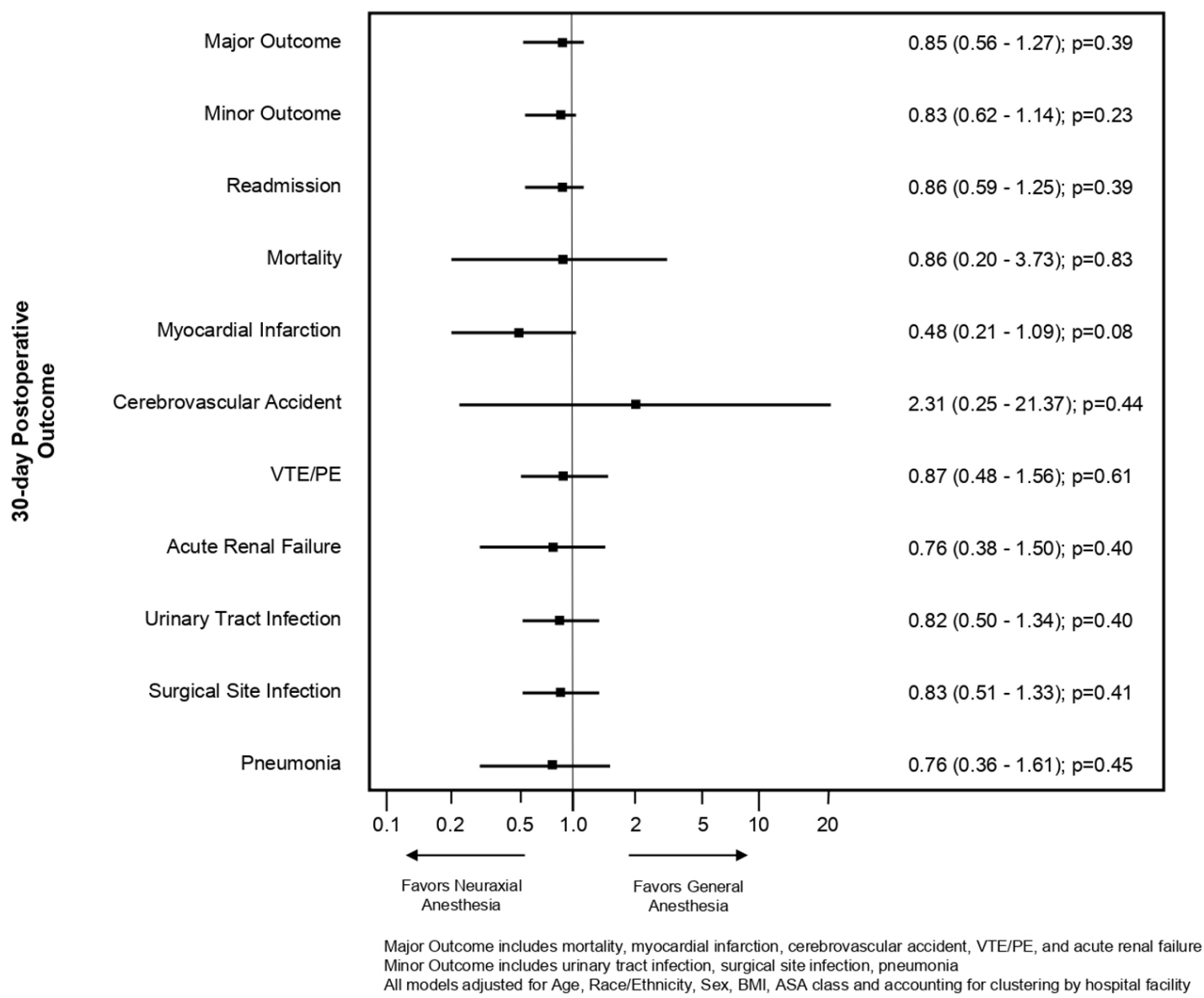

Figure 1 Adjusted OR of 30-day postoperative outcomes for outpatient total knee and hip arthroplasty. ASA, American Society of Anesthesiologists; $\mathrm{BMI}$, body mass index; PE, pulmonary embolism; VTE, venous thromboembolism.

anesthesia group compared with the neuraxial group $(75 \mathrm{~mL}$ (Q1-Q3: 45-100) vs $50 \mathrm{~mL}$ (Q1-Q3: 25-100); p<0.01). Rate of $\mathrm{RBC}$ transfusion was higher in the general anesthesia group $(0.6 \%$ vs $0.1 \% ; \mathrm{p}<0.01)$. The median surgical duration was higher by $10 \mathrm{~min}$ in the general anesthesia group, and median PACU length of stay was higher by $52 \mathrm{~min}$ in the neuraxial group. Patients in the general anesthesia group failed same day discharge at a higher percentage than those in the neuraxial

Table 2 30-day adverse postoperative outcomes for outpatient knee and hip arthroplasty

\begin{tabular}{|c|c|c|c|c|c|c|c|}
\hline \multirow[b]{3}{*}{ Postoperative outcome } & \multicolumn{2}{|c|}{ Anesthesia type } & \multirow[b]{3}{*}{$\chi^{2} p$-value } & \multicolumn{2}{|l|}{ Unadjusted OR } & \multicolumn{2}{|c|}{ Adjusted OR from hierarchical multivariable regression* } \\
\hline & \multirow{2}{*}{$\begin{array}{l}\text { Neuraxial } \\
n=10003\end{array}$} & \multirow{2}{*}{$\begin{array}{l}\begin{array}{l}\text { General } \\
\mathrm{n}=1520\end{array} \\
\mathrm{~N}(\%)\end{array}$} & & \multirow[b]{2}{*}{ OR $(95 \% \mathrm{Cl})$} & \multirow[b]{2}{*}{$P$ value } & \multirow[b]{2}{*}{ aOR $(95 \% \mathrm{Cl})$} & \multirow[b]{2}{*}{$P$ value } \\
\hline & & & & & & & \\
\hline Major outcomet & $175(1.8)$ & $35(2.3)$ & 0.13 & $0.75(0.52$ to 1.09$)$ & 0.13 & $0.85(0.56$ to 1.27$)$ & 0.39 \\
\hline Minor outcomeł & $325(3.3)$ & $62(4.1)$ & 0.09 & $0.79(0.60$ to 1.04$)$ & 0.09 & $0.83(0.62$ to 1.14$)$ & 0.23 \\
\hline Readmission & $233(2.3)$ & $45(3.0)$ & 0.14 & $0.78(0.57$ to 1.08$)$ & 0.14 & $0.86(0.59$ to 1.25$)$ & 0.39 \\
\hline \multicolumn{8}{|l|}{ Individual adverse outcomes } \\
\hline Mortality & $15(0.2)$ & $3(0.2)$ & $0.72 \S$ & $0.76(0.22$ to 2.63$)$ & 0.66 & $0.86(0.20$ to 3.73$)$ & 0.83 \\
\hline Myocardial infarction & $24(0.2)$ & $10(0.7)$ & $0.01 \S$ & $0.36(0.17$ to 0.76$)$ & 0.01 & $0.48(0.21$ to 1.09$)$ & 0.08 \\
\hline Cerebrovascular accident & $15(0.2)$ & $1(0.1)$ & 0.41 & $2.28(0.30$ to 17.27$)$ & 0.42 & 2.31 (0.25 to 21.37 ) & 0.44 \\
\hline VTE/PE & $92(0.9)$ & $16(1.0)$ & 0.61 & 0.87 (0.51 to 1.49$)$ & 0.62 & 0.87 (0.48 to 1.56$)$ & 0.61 \\
\hline Acute renal failure & $58(0.6)$ & $15(1.0)$ & 0.06 & 0.59 (0.33 to 1.04$)$ & 0.07 & $0.76(0.38$ to 1.50$)$ & 0.40 \\
\hline Urinary tract infection & $161(1.6)$ & $31(2.0)$ & 0.22 & $0.79(0.52$ to 1.16$)$ & 0.22 & 0.82 (0.50 to 1.34$)$ & 0.40 \\
\hline Surgical site infection & $131(1.3)$ & $25(1.6)$ & 0.29 & $0.79(0.52$ to 1.22$)$ & 0.29 & $0.83(0.51$ to 1.33$)$ & 0.41 \\
\hline Pneumonia & $43(0.4)$ & $10(0.7)$ & 0.22 & $0.65(0.32$ to 1.30$)$ & 0.22 & $0.76(0.36$ to 1.61$)$ & 0.45 \\
\hline
\end{tabular}

*All hierarchical multivariable regression models adjusted for age, race/ethnicity, sex, BMI, ASA class and accounting for clustering by hospital facility.

†Major outcome composite incidence of mortality, myocardial infarction, cerebrovascular event, VTE/PE, acute renal failure.

¥Minor outcome composite incidence of urinary tract infection, surgical site infection, pneumonia.

$\S$-value calculated with Fisher Exact Test.

VTE, venous thromboembolism; PE, pulmonary embolism; aOR, adjusted OR; ASA, American Society of Anesthesiologists. 
Table 3 Secondary outcomes for outpatient total knee and hip arthroplasty $\ddagger$

\begin{tabular}{|c|c|c|c|}
\hline \multirow[b]{2}{*}{ Postoperative outcome } & \multicolumn{2}{|c|}{ Anesthesia type } & \multirow[b]{2}{*}{$P$ value } \\
\hline & $\begin{array}{l}\text { Neuraxial } \\
n=10003\end{array}$ & $\begin{array}{l}\text { General } \\
n=1520\end{array}$ & \\
\hline \multicolumn{4}{|l|}{ Pain and PONV outcomes } \\
\hline Intraoperative opioid (MME), median (Q1-Q3) & $0(0-22.5)$ & $40(19-65)$ & $<0.01$ \\
\hline PACU opioid usage (MME), median (Q1-Q3) & $15(7.5-37.5)$ & $36(15-60)$ & $<0.01$ \\
\hline PACU average pain scores, median (Q1-Q3) & $1.5(1.1-2.3)$ & $2.5(1.8-3.2)$ & $<0.01$ \\
\hline PACU maximum pain scores, median (Q1-Q3) & $5(2-7)$ & $7(5-8)$ & $<0.01$ \\
\hline PACU PONV, n (\%) & $297(3.0)$ & $69(4.5)$ & $0.01^{*}$ \\
\hline \multicolumn{4}{|l|}{ Blood loss and transfusion outcomes } \\
\hline Intraoperative blood loss (mL), median (Q1-Q3) & $50(25-100)$ & $75(45-100)$ & $<0.01$ \\
\hline Transfusion (intraoperative and postoperative), $\mathrm{n}(\%)$ & $13(0.1)$ & $9(0.6)$ & $<0.01 \dagger$ \\
\hline Tranexamic acid administered, $\mathrm{n}(\%)$ & $9646(96.4)$ & $1492(98.2)$ & $<0.01^{*}$ \\
\hline \multicolumn{4}{|l|}{ Duration and admission outcomes } \\
\hline Surgical duration (min), median (Q1-Q3) & $76(66-87)$ & $86(74-101)$ & $<0.01$ \\
\hline Length of PACU stay (min), Median (Q1-Q3) & $188(111-278)$ & $136(89-225)$ & $<0.01$ \\
\hline Admitted after surgery, $\mathrm{n}(\%)$ & $2336(23.4)$ & $502(33.0)$ & $<0.01^{*}$ \\
\hline
\end{tabular}

* $\mathrm{P}$ value calculated using $\chi^{2}$ test.

$\dagger P$ value calculated using Fisher exact test.

$\ddagger$ Pain scores reported by Numeric Rating Scale, scale from 0 to 10 .

$\S A l l p$ values are calculated using Wilcoxon rank-sum test unless indicated otherwise.

MME, morphine milligram equivalents; PACU, postanesthesia care unit; PONV, postoperative nausea and vomiting; Q, quartile.

anesthesia group ( $33 \%$ vs $23.4 \%$; $\mathrm{p}<0.01)$. Patient characteristics in those who were discharged the same day as surgery and those who failed same day discharge were examined in online supplemental table 2 .

\section{DISCUSSION}

Our study was motivated by the shift in practice towards outpatient total joint arthroplasty and our gap in knowledge about the impact of anesthesia type on adverse postoperative outcomes in this patient population. Investigating 11523 patients who underwent outpatient primary total hip or knee joint arthroplasty from 2017 to 2019, we found no difference in 30-day major complications, 30-day minor complications, and 30-day readmission rates between patients who received neuraxial anesthesia compared with those who received general anesthesia. While more serious adverse events did not differ between groups, several secondary outcomes suggest benefits in patients undergoing surgery with neuraxial anesthesia. Patients undergoing surgery with general

Table 4 Prevalence of non-opioid adjunct administered among outpatient total knee and hip arthroplasty

\begin{tabular}{|c|c|c|c|}
\hline \multirow[b]{3}{*}{ Medication } & \multicolumn{2}{|c|}{ Anesthesia type } & \multirow[b]{3}{*}{$\chi^{2} p$-value } \\
\hline & $\begin{array}{l}\text { Neuraxial } \\
n=10003\end{array}$ & $\begin{array}{l}\text { General } \\
n=1520\end{array}$ & \\
\hline & $\mathrm{N}(\%)$ & $\mathrm{N}(\%)$ & \\
\hline $\begin{array}{l}\text { Non-steroidal anti- } \\
\text { inflammatory }\end{array}$ & $7904(79.0)$ & $641(42.2)$ & $<0.01$ \\
\hline Acetaminophen & $9447(94.4)$ & 1408 (92.6) & $<0.01$ \\
\hline Gabapentinoids & $1299(13.0)$ & $496(32.6)$ & $<0.01$ \\
\hline Ketamine & $1627(16.3)$ & $771(50.7)$ & $<0.01$ \\
\hline Alpha-2 agonist & $1090(10.9)$ & $260(17.1)$ & $<0.01$ \\
\hline Magnesium sulfate & $435(4.4)$ & $543(35.7)$ & $<0.01$ \\
\hline Corticosteroid & $6747(67.5)$ & $1198(78.8)$ & $<0.01$ \\
\hline Periarticular injection & $5646(56.4)$ & $700(46.1)$ & $<0.01$ \\
\hline Nerve block & 7745 (77.4) & $1152(75.8)$ & 0.16 \\
\hline
\end{tabular}

anesthesia had more pain in the PACU despite receiving higher amounts of intraoperative and postoperative opioids and more frequent use of non-opioid adjuncts. Higher opioid administration might have contributed to a higher incidence of moderate to severe PONV in the general anesthesia group. Despite consistent use of antifibrinolytic agents (table 3), we were still able to demonstrate a higher estimated blood loss and a higher transfusion rate in the general anesthesia group. While shorter PACU recovery times in the general anesthesia group appear to suggest faster recovery, these patients were nonetheless more likely to fail discharge on the day of surgery. Although we would like to attribute these secondary findings to anesthesia type received, the general anesthesia group did have a higher percent of patients with higher comorbidities (ASA class $\geq \mathrm{III}$ and $\mathrm{CCI} \geq 3$ ), which was positively associated with failed same day discharge (online supplemental table 2).

An anesthetic plan that improves patient outcomes, reduces harm and helps facilitate discharge home is important in deciding on the type of anesthesia for outpatient total joint arthroplasty, and can also affect patient satisfaction. ${ }^{23}$ Multiple large database studies ${ }^{13}{ }^{24-27}$ have compared anesthesia type in total hip and knee arthroplasty. Memtsoudis et $a l^{13}$ examined 382236 patients in a national database and compared perioperative outcomes between anesthesia techniques for total hip and knee arthroplasty. They found neuraxial anesthesia to be a positive modifier in reducing perioperative complications. General anesthesia, when compared with neuraxial anesthesia, had significant increased odds of multiple major postoperative complications and 30-day postoperative mortality. However, unlike their study and results from other large database studies, ${ }^{24-27}$ we did not find any difference in serious complications between anesthesia types in our study. The benefits of neuraxial anesthesia have been attributed to its physiological effects such as a reduced sympathetic stress response from surgery, reduced immunomodulation, and the avoidance of mechanical ventilation associated with general anesthesia. ${ }^{10}$ However, these benefits of neuraxial anesthesia may be more pronounced in patients with higher 
comorbidities. $^{25}$ The selection of healthier patients for outpatient surgery is likely to result in a lower overall rate of complications, making it more challenging to demonstrate differences in complication rates between anesthesia techniques. In addition, the improved surgical techniques and shorter duration of hospital stays may further decrease the risk of complications. ${ }^{28}$

Anesthesia type can also impact hospital length of stay and is an important consideration for outpatient total joint surgery. Studies have shown that neuraxial anesthesia is associated with a reduction in length of hospital stay when compared with general anesthesia. ${ }^{132425}$ For example, a recent study by Kelly et $a l^{29}$ comparing neuraxial to general anesthesia in 500 total hip arthroplasty patients at their institution found a significant reduction in length of hospital stay in the neuraxial group (32.7 hours, SD 14.8 vs 38.1 hours, SD 24, p=0.003). However, these studies did not exclusively look at outpatient total joint patients where patients are expected to be discharged from the PACU. In this setting, neuraxial anesthesia may not be as favorable. Longer PACU recovery times in patients undergoing neuraxial anesthesia have been previously reported ${ }^{30}$ and is considered the Achilles heel of this anesthetic approach. Slow recovery from residual leg weakness and urinary retention are known to increase the time to meet discharge criteria. Since PACU turn over time is important in an ambulatory surgery center, this disadvantage has prevented neuraxial anesthesia from becoming the standard of care for ambulatory surgery of the lower extremity. Nonetheless, we feel that this disadvantage is being more than compensated for by the reduced rate of unplanned hospital admissions in the neuraxial anesthesia group. This finding was not entirely surprising considering patients with higher pain scores and PONV are more likely to be admitted after ambulatory surgery. Consequently, within our health system, neuraxial anesthesia continues to be the preferred anesthetic modality as reflected in the higher rates of neuraxial versus general anesthesia in our study cohort.

Our study had several strengths that included a large sample size, a multicentered community-based setting and a strong statistical analysis that utilized hierarchical multivariable regression analysis models. These strengths may help generalize our study's findings to other community-based practices. Our study's findings also have significant implications to the perioperative care of patients undergoing outpatient total joint arthroplasty and support the feasibility and benefits of the use of neuraxial anesthesia in this patient population.

There are several limitations in our study to be noted. Our null results to detect statistically significant differences in major and minor complications may be due to inadequate power. Therefore, our findings should be interpreted as exploratory, not confirmatory. However, the observed differences were small, suggesting that both anesthetic approaches are associated with a similar number of complications. Another limitation includes our institution's preference for selecting neuraxial anesthesia as seen by a large percentage of patients in this group, and thus the choice for general anesthesia may be for reasons that precluded a patient from neuraxial anesthesia. The retrospective design of the study subjects it to numerous biases, and despite adjustment and clustering for hospital center, there may be residual confounding factors. Available information on the reasons for extended PACU stay or the reason for admission could have supported our assumptions about the effects of neuraxial anesthesia on outcome. In our setting, surgeries were performed in a hospital setting, which may have resulted in different patient selection than in an isolated ambulatory surgery center. Since unplanned admissions can be managed easily, even patients who may be marginal for same day surgery may have been scheduled. Although our health system is integrated and most patients return to our hospitals if issues arise, an incomplete capture of 30-day adverse postoperative outcomes for those patients who present to outside hospitals presents a limitation to our study. Finally, our practice in an integrated healthcare system may be unique and care elements not accounted for could have influenced postoperative outcomes.

\section{CONCLUSION}

Our study investigating patients who underwent outpatient primary total hip or knee joint arthroplasty demonstrated no difference in 30-day postoperative major and minor complications and 30-day readmission rates between general anesthesia and neuraxial anesthesia. However, neuraxial anesthesia was associated with improved secondary postoperative patient outcomes leading to improved rates of same day discharge. Our study's findings support the current practice that favors neuraxial anesthesia over general anesthesia for outpatient joint arthroplasty and highlights the benefits of neuraxial anesthesia in this patient population.

Contributors EY acted as the guarantor for this manuscript and accepts full responsibility for the work, conduct of the study, had access to the data and controlled the decision to publish. EY, CW, KN and MB conceived and designed the study; EY obtained funding for the study; EY and JW had full access to the data in the study and takes responsibility for the integrity and the accuracy of the data analysis; EY and JW were involved in acquisition of data. All authors were involved in analysis and interpretation of the data. All authors helped draft the manuscript and were involved in critical revisions of the manuscript for important intellectual content. All authors gave approval for the final manuscript.

Funding This study was funded by Kaiser Permanente Northern California Community Health Grant.

Disclaimer The funder had no role in the design and conduct of the study; collection, analysis and interpretation of the data; preparation, review or approval of the manuscript and decision to submit the manuscript for publication. The views expressed in this article are those of the authors and do not necessarily reflect the opinions of the authors' institutions.

\section{Competing interests None declared.}

Patient consent for publication Not required.

Ethics approval This study was approved by the Kaiser Foundation Research Institute's Institutional Review Board and the requirement for written informed consent was waived (IRB\# 1419947-2)

Provenance and peer review Not commissioned; externally peer reviewed.

Data availability statement All data relevant to the study are included in the article or uploaded as supplementary information. Data are not publicly accessible. Data are available upon reasonable request pending approval from corresponding author's institutional review board.

Supplemental material This content has been supplied by the author(s). It has not been vetted by BMJ Publishing Group Limited (BMJ) and may not have been peer-reviewed. Any opinions or recommendations discussed are solely those of the author(s) and are not endorsed by BMJ. BMJ disclaims all liability and responsibility arising from any reliance placed on the content. Where the content includes any translated material, BMJ does not warrant the accuracy and reliability of the translations (including but not limited to local regulations, clinical guidelines, terminology, drug names and drug dosages), and is not responsible for any error and/or omissions arising from translation and adaptation or otherwise.

Open access This is an open access article distributed in accordance with the Creative Commons Attribution Non Commercial (CC BY-NC 4.0) license, which permits others to distribute, remix, adapt, build upon this work non-commercially, and license their derivative works on different terms, provided the original work is properly cited, an indication of whether changes were made, and the use is noncommercial. See: http://creativecommons.org/licenses/by-nc/4.0/.

\section{ORCID iD}

Edward Yap http://orcid.org/0000-0001-7992-5572 


\section{REFERENCES}

1 Ethgen $\mathrm{O}$, Bruyère $\mathrm{O}$, Richy $\mathrm{F}$, et al. Health-related quality of life in total hip and total knee arthroplasty. A qualitative and systematic review of the literature. J Bone Joint Surg Am 2004;86:963-74.

2 Meneghini R, Gibson W, Halsey D, et al. The American association of hip and knee surgeons, hip Society, knee Society, and American Academy of orthopaedic surgeons position statement on outpatient joint replacement. J Arthroplasty 2018;33:3599-601.

3 Burn E, Edwards CJ, Murray DW, et al. Trends and determinants of length of stay and hospital reimbursement following knee and hip replacement: evidence from linked primary care and NHS hospital records from 1997 to 2014. BMJ Open 2018;8:e019146.

4 Carey K, Morgan JR, Lin M-Y, et al. Patient Outcomes Following Total Joint Replacement Surgery: A Comparison of Hospitals and Ambulatory Surgery Centers. J Arthroplasty 2020;35:7-11.

5 Weyker PD, Webb CA-J. Establishing a patient centered, outpatient total joint home recovery program within an integrated healthcare system. Pain Manag 2020;10:23-41.

6 Li J, Rubin LE, Mariano ER. Essential elements of an outpatient total joint replacement programme. Curr Opin Anaesthesiol 2019;32:643-8.

7 Lovett-Carter D, Sayeed Z, Abaab L, et al. Impact of outpatient total joint replacement on postoperative outcomes. Orthop Clin North Am 2018;49:35-44.

8 Bovonratwet P, Ondeck NT, Nelson SJ, et al. Comparison of outpatient vs inpatient total knee arthroplasty: an ACS-NSQIP analysis. J Arthroplasty 2017;32:1773-8.

9 Courtney PM, Boniello AJ, Berger RA. Complications following outpatient total joint arthroplasty: an analysis of a national database. J Arthroplasty 2017;32:1426-30.

10 Rodgers A, Walker N, Schug S, et al. Reduction of postoperative mortality and morbidity with epidural or spinal anaesthesia: results from overview of randomised trials. BMJ 2000;321:1493.

11 Guay J, Choi PT, Suresh S, et al. Neuraxial anesthesia for the prevention of postoperative mortality and major morbidity: an overview of Cochrane systematic reviews. Anesth Analg 2014;119:716-25.

12 Memtsoudis SG, Cozowicz C, Bekeris J, et al. Anaesthetic care of patients undergoing primary hip and knee arthroplasty: consensus recommendations from the International consensus on Anaesthesia-Related outcomes after surgery group (ICAROS) based on a systematic review and meta-analysis. $\mathrm{Br} J$ Anaesth 2019;123:269-87

13 Memtsoudis SG, Sun X, Chiu Y-L, et al. Perioperative comparative effectiveness of anesthetic technique in orthopedic patients. Anesthesiology 2013;118:1046-58.

14 Mauermann WJ, Shilling AM, Zuo Z. A comparison of neuraxial block versus general anesthesia for elective total hip replacement: a meta-analysis. Anesth Analg 2006:103:1018-25.
15 Kort NP, Bemelmans YFL, Schotanus MGM. Outpatient surgery for unicompartmental knee arthroplasty is effective and safe. Knee Surg Sports Traumatol Arthrosc 2017;25:2659-67.

16 Meneghini RM, Ziemba-Davis M, Ishmael MK, et al. Safe Selection of Outpatient Joint Arthroplasty Patients With Medical Risk Stratification: the "Outpatient Arthroplasty Risk Assessment Score". J Arthroplasty 2017;32:2325-31.

17 Berger RA, Sanders SA, Thill ES, et al. Newer anesthesia and rehabilitation protocols enable outpatient hip replacement in selected patients. Clin Orthop Relat Res 2009;467:1424-30

18 Harsten A, Kehlet $\mathrm{H}$, Toksvig-Larsen S. Recovery after total intravenous general anaesthesia or spinal anaesthesia for total knee arthroplasty: a randomized trial. $\mathrm{Br} J$ Anaesth 2013;111:391-9.

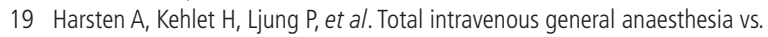
spinal anaesthesia for total hip arthroplasty: a randomised, controlled trial. Acta Anaesthesiol Scand 2015:59:298-309.

20 Schwenk ES, Johnson RL. Spinal versus general anesthesia for outpatient joint arthroplasty: can the evidence keep up with the patients? Reg Anesth Pain Med 2020;45:934-6.

21 Cao J, Zhang S. Multiple comparison procedures. JAMA 2014;312:543-4.

22 Althouse AD. Adjust for multiple comparisons? it's not that simple. Ann Thorac Surg 2016;101:1644-5

23 Myles PS, Williams DL, Hendrata M, et al. Patient satisfaction after anaesthesia and surgery: results of a prospective survey of 10,811 patients. $\mathrm{Br} J$ Anaesth 2000;84:6-10

24 Helwani MA, Avidan MS, Ben Abdallah A, et al. Effects of regional versus general anesthesia on outcomes after total hip arthroplasty: a retrospective propensitymatched cohort study. J Bone Joint Surg Am 2015;97:186-93.

25 Pugely AJ, Martin CT, Gao Y, et al. Differences in short-term complications between spinal and general anesthesia for primary total knee arthroplasty. J Bone Joint Surg Am 2013;95:193-9.

26 Liu J, Ma C, Elkassabany N, et al. Neuraxial anesthesia decreases postoperative systemic infection risk compared with general anesthesia in knee arthroplasty. Anesth Analg 2013;117:1010-6.

27 Warren J, Sundaram K, Anis $\mathrm{H}$, et al. Spinal anesthesia is associated with decreased complications after total knee and hip arthroplasty. J Am Acad Orthop Surg 2020;28:e213-21.

28 Sarpong NO, Boddapati V, Herndon CL, et al. Trends in length of stay and 30-day complications after total knee arthroplasty: an analysis from 2006 to 2016. J Arthroplasty 2019:34:1575-80.

29 Kelly ME, Turcotte JJ, Aja JM, et al. General vs neuraxial anesthesia in direct anterior approach total hip arthroplasty: effect on length of stay and early pain control. J Arthroplasty 2021;36:1013-7

30 Mulroy MF, Larkin KL, Hodgson PS, et al. A comparison of spinal, epidural, and general anesthesia for outpatient knee arthroscopy. Anesth Analg 2000;91:860-4. 